\title{
Leprosy in Post Elimination Period: An Experience in a Single Tertiary Care Centre in Kathmandu, Nepal
}

\author{
Paudel U, Parajuli S \\ Department of Dermatology and Venereology, Maharajgunj Medical Campus, Institute of Medicine, Kathmandu
}

\begin{abstract}
Introduction: Leprosy elimination was declared by Government of Nepal almost a decade back.

Objective: To evaluate the clinical and epidemiological profiles of leprosy patients in post elimination period

Material and Methods: Analysis of medical records of all clinically diagnosed and newly registered cases of leprosy attending Dermatology outpatient department of Tribhuvan University Teaching Hospital, Kathmandu, Nepal from 1st April 2017 to 31st March 2018 was done.

Results: Hospital based prevalence of Leprosy was found to be $0.24 \%$, with males outnumbering females ( $63.6 \%$ vs $36.4 \%)$. The most common age group affected was $45-59$ years with hypo-aesthetic patches/plaques and erythematous anaesthetic /hypoaesthetic patches (36.4\% each) being the most common presentation. Overall, borderline leprosy was the most common diagnosis (borderline tuberculoid ,29.5\%, borderline borderline, $6.8 \%$, borderline lepromatous, $11.36 \%$ ). Slit skin smear positivity was found in $50 \%$ of cases.

Conclusions: Leprosy still remains a challenge for clinicians in Nepal though elimination has been achieved. A constant evaluation, monitoring and case detection should be still pursued with health education in order to make timely diagnosis and prevent deformities.
\end{abstract}

Key words: Leprosy; Nepal; Public health

\section{Introduction}

eprosy is a major public health problem in Lmany countries including Nepal even though its elimination was declared on 19th January $2010 .{ }^{1}$ The objective of this study was to evaluate the clinical and epidemiological profiles of leprosy patients in post elimination period among those attending Dermatology outpatient department of Tribhuvan University Teaching Hospital, Kathmandu, Nepal, the largest referral centre of the country.

\section{Materials and Methods}

Retrospective analysis of the medical records of all clinically diagnosed and newly registered cases of leprosy attending the Dermatology outpatient department of Tribhuvan University Teaching Hospital from $1^{\text {st }}$ April 2017 to $31^{\text {st }}$ March 2018 was done. The

\section{Address of Correspondence:}

Dr Sudip Parajuli

Assistant Professor,

Department of Dermatology and Venereology,

Maharajgunj Medical Campus, Institute of Medicine, Kathmandu, Nepal

E-mail: sudipparajuli@gmail.com study was approved by the institutional review board. The data were analyzed for age and sex distribution, clinical features at presentation, nerve involvement, reactions, deformities, history of contact, slit skin smear positivity and histopathological diagnoses.

\section{Results}

A total number of $44(0.24 \%$ of total new cases attending Dermatology outpatient department, Tribhuvan University Teaching Hospital during the study period) patients were diagnosed as Leprosy

Submitted: $15^{\text {th }}$ July 2018

Accepted: $1^{\text {st }}$ November 2018

Published: $31^{\text {st }}$ March 2019

\section{How to cite this article}

Paudel U, Parajuli S. Leprosy in post elimination period: an experience in a single tertiary care centre in Kathmandu, Nepal. Nepal Journal of Dermatology, Venereology and Leprology. 2019;17(1):63-5. doi: http://dx.doi.org/10.3126/ njdvl.v17i1.23388

\section{(c) (i)}

Licensed under CC BY 4.0 International License which permits use, distribution and reproduction in any medium, provided the original work is properly cited. 
in this period with $63.6 \%(n=28)$ males and $36.4 \%$ $(n=16)$ females. The most common age group affected was 45-59 years constituting about $36.4 \%$ of cases (Table 1). Hypo-aesthetic patches/plaques (36.4\%), erythematous anaesthetic/hypoaesthetic patches $(36.4 \%)$ was the most common presentation (Table 2). Multiple lesions were seen at first presentation in 27 patients (61.4\%) and single lesion in 17 patients (38.6\%). Multiple nerves were involved in 19 (43.2\%) patients, single in 10 (22.7\%) patients and none in 15 (34.1\%) patients. Type1 reaction was seen in seven cases and type 2 reactions were seen in three cases of patients at presentation. Claw hands alone were seen in three cases, both claw hands and lagophthalmus was seen in one case while lagophthalmus alone was seen in only one case. History of contact with Leprosy patients was present in three cases, family members were involved in two cases, one being a three-year old child. History of neighbor taking multidrug therapy (MDT) was present in one case only. Slit skin smear was positive in $50 \%$ of the cases. Histopathologically, Tuberculoid leprosy was diagnosed in $33 \%$ of the cases.

\section{Discussion}

Our study reviewed hospital based clinical presentation of leprosy in one year period after declaration of elimination of leprosy by Government of Nepal, where we found hospital based frequency of leprosy to be $0.24 \%$. This prevalence is similar to one of the study done in another tertiary centre of Kathmandu by Joshi $S$, who found it to be around $0.2 \% .^{2}$ Males outnumbered females similar to the findings from other studies by Swarnakumari G et al, Santaram and Porichha, and Singh et al. ${ }^{3-5}$ This could be because males work outdoor and gets exposed to the disease. The youngest patient in our study was of threee years, son of affected father, which indicates ongoing transmission of the disease in the community.

Table 1: Age group of patients with Leprosy

\begin{tabular}{|c|c|c|}
\hline Age Group & Number & Percent \\
\hline$\leq 14$ yrs & 3 & 6.8 \\
\hline $15-29 y r s$ & 14 & 31.8 \\
\hline $30-44$ yrs & 8 & 18.2 \\
\hline $45-59$ yrs & 16 & 36.4 \\
\hline$\geq 60 y r s$ & 3 & 6.8 \\
\hline Total & $\mathbf{4 4}$ & $\mathbf{1 0 0 . 0 0}$ \\
\hline
\end{tabular}

Table 2: Clinical feature at presentation

\begin{tabular}{|l|c|c|c|c|c|c|c|}
\hline \multirow{2}{*}{ Clinical Diagnosis } & \multicolumn{9}{|c|}{ Slit skin smear } & \multirow{2}{*}{ Total } \\
\cline { 2 - 8 } & Negative & $\mathbf{1 +}$ & $\mathbf{2 +}$ & $\mathbf{3 +}$ & $\mathbf{4 +}$ & $\mathbf{6 +}$ & $\mathbf{5}$ \\
\hline Indeterminate (11.3\%) & 5 & 0 & 0 & 0 & 0 & 0 & 11 \\
\hline TT (25\%) & 8 & 0 & 3 & 0 & 0 & 0 & 13 \\
\hline BT (29.5\%) & 8 & 1 & 2 & 2 & 0 & 0 & 3 \\
\hline BB (6.8\%) & 0 & 0 & 3 & 0 & 0 & 0 & 5 \\
\hline BL (11.36\%) & 0 & 0 & 2 & 1 & 2 & 0 & 6 \\
\hline LL (13.6\%) & 0 & 0 & 0 & 0 & 3 & 3 & 0 \\
\hline Pure Neuritic (2.2\%) & 1 & 0 & 0 & 0 & 0 & 0 & 1 \\
\hline Total & $\mathbf{2 2}$ & $\mathbf{1}$ & $\mathbf{1 0}$ & $\mathbf{3}$ & $\mathbf{5}$ & $\mathbf{3}$ & $\mathbf{4 4}$ \\
\hline
\end{tabular}

Table 3: Clinical diagnosis versus slit skin smear positivity.

\begin{tabular}{|l|c|c|}
\hline Presentations & Number & Percent \\
\hline Hypopigmented anaesthetic/hypoaesthetic plaques & 16 & 36.4 \\
\hline Erythematous anaesthetic/hypoaesthetic plaques & 16 & 36.4 \\
\hline Painless ulcers/bullae & 5 & 11.4 \\
\hline Tender nodules & 3 & 6.8 \\
\hline Asymptomatic erythematous papules and plaques & 3 & 6.8 \\
\hline Others & 1 & 2.3 \\
\hline \multicolumn{1}{|c|}{ Total } & $\mathbf{4 4}$ & $\mathbf{1 0 0}$ \\
\hline
\end{tabular}


Around $36.4 \%$ of patients presented with hypo -pigmented hypo-aesthetic patches/plaques and $36.4 \%$ presented with erythematous anaesthetic patch/plaque with clinical diagnosis of Indeterminate in (11.3\%), Tuberculoid (TT) in (25\%), borderline tuberculoid (BT) leprosy (LL) in (29.5\%), borderline (BB) in (6.8\%), borderline lepromatous(BL) Leprosy in $(11.36 \%)$, Lepromatous (LL) in $(13.6 \%)$, and pure neuritic leprosy in ( $2.2 \%$ ) (Figure 3 ). This observation differs from different studies, however, the borderline leprosy (BT and BL), seems to be more common form of presentation in all studies. The fact that lepromatous leprosy though less in number compared to tuberculoid pole in our study, constituting one of the major bulk of patient is alarming to us, as they are the main source of transmission in the community. Furthermore, slit skin smear being positive in $50 \%$ (Table 3 ), ie. multibacillary cases, supports the above observation.

Type $1(15.9 \%)$ reaction was more common than type $2(6.8 \%)$ reaction in our study similar to that found by Arora et al, well explained by the fact upgrading reactions were present in majority of our cases of $\mathrm{BT}$, $\mathrm{BB}$, and BL patients. ${ }^{6}$

Out of 44 cases we had five (11.36\%) cases of deformities. In a study done by Bhattarai $S$ et al in eastern part of Nepal, a significant high number (37.4\%) of disability, higher than our study was seen. ${ }^{7}$ Deformities in these two studies can be attributed to delay in diagnosis or delay in health seeking behavior in these patients despite the advocacy of the state for early detection of this disease.

The data represents retrospective data in a single centre for just a period of one year. Though the frequency appears to be 24 per 10000 people, a quite alarming figure, the results cannot be generalized unless we carry out a prospective study in multi -centre in co-ordination with Government of Nepal.

\section{Conclusion}

Leprosy still remains a challenge for clinicians in Nepal though elimination has been achieved. Childhood case detection shows ongoing transmission in the community whereas detection of deformities points towards delay in diagnosis. We still need to work for case detection and prevention of transmission and prevention of leprosy in Nepal.

Financial disclosur: None.

Conflict of interest to disclosure: None declared.

\section{References}

1. Department of health services. [Internet]. Kathmandu: Government of Nepal, Ministry of health and population. Annual Report 2016/17.p.149-162. Available from: https://dohs. gov.np/wp-content/uploads/2018/04/Annual_ Report_2073-74.pdf [Accessed on 15th March 2018].

2. Joshi S, Jha AK, Shrestha S, Thapa DP. Leprosy before and after national elimination at Nepal Medical College teaching Hospital. A 12 year audit. Nepal Med COII J. 2017;19(3):142-6.

3. Swarnakumari G, Narasimha Rao TV, Ngeswaramma S, Vani T, RamMohan Ch, Naik Neenavathu R. A study of clinical profile of leprosy in post elimination era. IOSR-Journal of Dental and Medica Sciences. 2015:14(11):4-12.

4. Santaram V, Porichha D. Reaction cases treated at the regional leprosy training and research institute. Indian J lepr. 2004;76(4):310-20.

5. Singh S, Sinha AK, Banergee BG, Jaswal N. Participation level of the leprosy patients in society. Indian J lepr. 2009;81(4):181-7.

6. Arora M, Katoch K, Natrajan M, Kamal R, Yadav VS. Changing Profile of disease in leprosy patients diagnosed in a tertiary care centre during years 1995-2000. Indian J lepr. 2008;80;257-65.

7. Bhattarai S, Agrawal S, Rijal A, Marhatta S. Leprosy after elimination. A BPKIHS experience. NJDVL 2013;11:41-4. https://doi.org/10.3126/ njdvl.v11i1.7933 